\title{
Ridge Preservation in Immediate Implant Site Using Partial Extraction Therapy (Socket Shield Technique)
}

Lakshmi R $^{1 *}$, S Anilkumar ${ }^{2}$, Faiz Ansari ${ }^{1}$, Muhnisa Muhamedali ${ }^{1}$

${ }^{1}$ Senior Resident, Department of Prosthodontics, Government Dental College, Gandhinagar, Kottayam, Kerala 686008, India

${ }^{2}$ Professor and Head of Department, Department of Prosthodontics, Government Dental College, Gandhinagar, Kottayam, Kerala 686008, India

DOI: $10.36347 /$ sjds.2020.v07i12.005

| Received: 14.12.2020 | Accepted: 22.12.2020 | Published: 29.12.2020

*Corresponding author: Lakshmi $\mathrm{R}$

Abstract

Case Report

Post extraction buccopalatal ridge collapse is a significant challenge in restorative and implant dentistry. None of the available ridge preservation/ augmentation procedures could restore the pink-white esthetics up to the mark and finally result in partial or total ridge collapse. PARTIAL EXTRACTION THERAPY (PET), a newly introduced term into literature and clinical environment aims to retain the tooth root itself. SOCKET SHIELD TECHNIQUE, introduced by Hurzeler in 2010 is one among PET, where it retains buccal/ facial root section at immediate implant placement. The purpose of this article is to report two cases where unrestorable maxillary anteriors were restored with immediate implant placement retaining buccal shield.

Keywords: Socket Shield, Partial Extraction Therapy, Immediate implant placement.

Copyright $\odot 2020$ The Author(s): This is an open-access article distributed under the terms of the Creative Commons Attribution 4.0 International License (CC BY-NC 4.0) which permits unrestricted use, distribution, and reproduction in any medium for non-commercial use provided the original author and source are credited.

\section{INTRODUCTION}

The alveolar process which is a tooth dependent tissue, develops in conjunction with eruption of tooth; its volume and contour is determined by the root form, axis of eruption and resultant inclination. Subsequent to extraction of tooth, the alveolar process undergoes atrophy due to the destruction of Bundle Bone-Periodontal Ligament (BB-PDL) complex [1]. Araujo et al., in an invitro study evaluating post extraction dimensional changes of alveolar ridge on Mongrel dogs, concluded that the reduction of height of walls are more prominent on buccal than on the lingual aspect of extraction socket [2]. In spite of the numerous ridge preservation and augmentation procedures available, extraction of a tooth will ultimately result in partial or total ridge collapse. A viable alternative is to retain part of the tooth root itself or Partial Extraction Therapy. By retaining the tooth root and its attachment to bone, the BB-PDL complex with its vascular supply may be maintained. Partial Extraction Therapies (PET) represent a subgroup of precollapse interventions that collectively use the tooth itself to offset the loss of alveolar tissue [3]. Root Submergence, Socket Shield, Pontic Shield, Proximal Socket Shield, Root T Belt are a few techniques which retains a part of tooth and thus collectively be called Partial Extraction Therapies[3, 4].
Root Submergence Technique retains decoronated tooth roots. This technique is used to maintain the alveolar ridge beneath complete dentures and also for pontic sites development beneath fixed partial dentures. The submerged root maintains the periodontal attachment complex, thereby preventing the resorption of the alveolar bone on the buccal and lingual walls, as well as on the interproximal areas [5, 6]. Root Submergence can be vital or non-vital. In case of any active infection of the root, the apical area must first be resolved by endodontic treatment. An adequately root canal treated tooth or a vital, infectionfree tooth root may be submerged. The tooth is decoronated at the level of the crest of bone and the coronal root is hollowed to mimic the future ovate pontic. The site is to heal for a minimum of 3 months prior to any pontic pressure of the tissue overlying the tooth root. A vertical fracture or apical pathology may contraindicate root submergence. However, in such a situation the clinician can switch to Pontic Shield [3, 7].

Pontic Shield technique preserves the alveolar ridge by retaining the buccal or facial root section. The palatal root fragment is extracted and the extraction socket is grafted with a slow-resorbing bone substitute material and the tooth socket is sealed with soft tissue graft. Pontic pressure may gradually be applied after a period of 3 months similar to that of Root Submergence Technique [3]. 
Partial Extraction Therapy can also be made use in implant dentistry, particularly in Immediate Implant Placement. Immediate implant placement can minimize bone loss at extraction site, but it does not stop the process of socket or ridge remodelling. Botticelli et al., in 2004 studied dimensional alterations of hard tissues that occur following tooth extraction and immediate placement of implants. During the first four months of healing, horizontal resorption of buccal bone amounted to about $56 \%$ and the corresponding resorption of lingual/palatal bone was $30 \%$ [8].

Hürzeler et al., in 2010 introduced the Socket Shield Technique, where the facial or buccal root section is maintained at immediate implant placement. It is typically indicated in maxillary anteriors. Following adequate anesthesia of the site planned for immediate implant placement, the tooth is sectioned mesiodistally into facial and palatal halves, in the ratio 1:2 using an irrigated long shank root resection bur. The corono-apical extension of the facial half is one third the former root length. An endodontic instrument in the root canal may be used to guide the sectioning process. The palatal root section is elevated using periotome inserted into palatal periodontal ligament space. Then palatal root is delivered using a microforceps leaving the facial root section in situ. While its attachment to socket remains undisturbed, the root section is refined and prepared, any pathology present is cleared from the tooth apex. The labial root section is then inspected for any mobility. The implant is then placed palatal to the socket shield and the buccal jump gap is filled with bone substitutes [3].

This article describes two cases where failing tooth is preserved by the "socket shield technique" and immediate implant placement.

\section{CASE REPORT - 1}

A 26 year old female patient reported to Government Dental College, Kottayam with a chief complaint of fractured upper front teeth. History revealed fracture of teeth following a Road Traffic Accident one day before and had reported to a nearby hospital to treat lacerations over the face and arms. But no dental treatment was undertaken. Her medical history was non-contributory. Intra oral hard tissue examination revealed an Ellis class III fracture on 11, class VIII fracture on 22 and Grade I mobility of 21. 11, 21 and 22 were tender to percussion (Fig-1). IOPA radiograph of 22 showed normal apex with fracture of crown at the level of crest of alveolar bone (Fig-2). Preoperative CBCT demonstrated thin buccal plate and horizontal fracture of 22 at the level of alveolar crest (Fig-3).

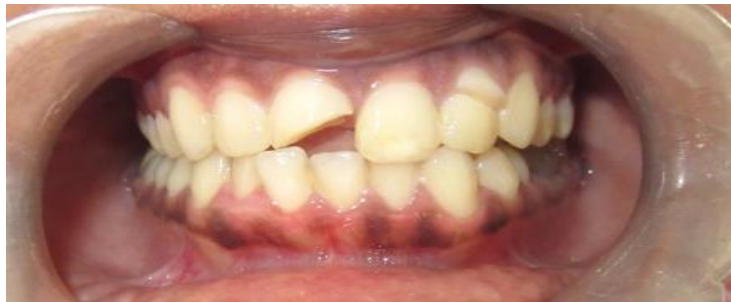

Fig-1: Preoperative Photograph

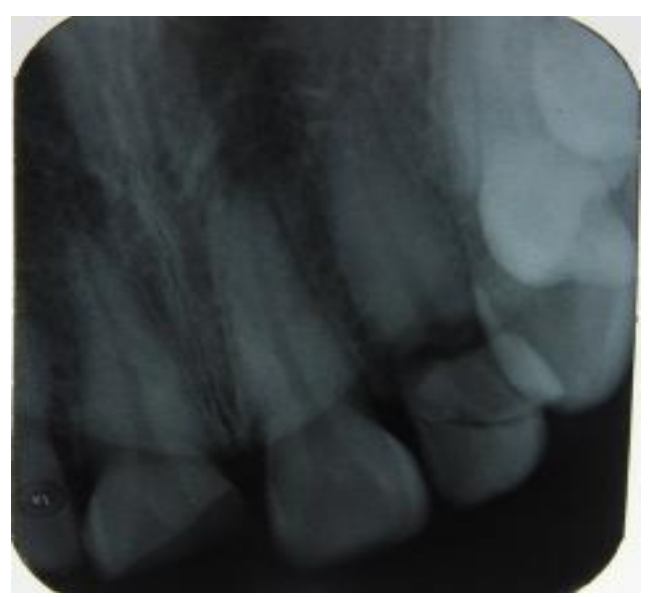

Fig-2: Preoperative radiograph 22
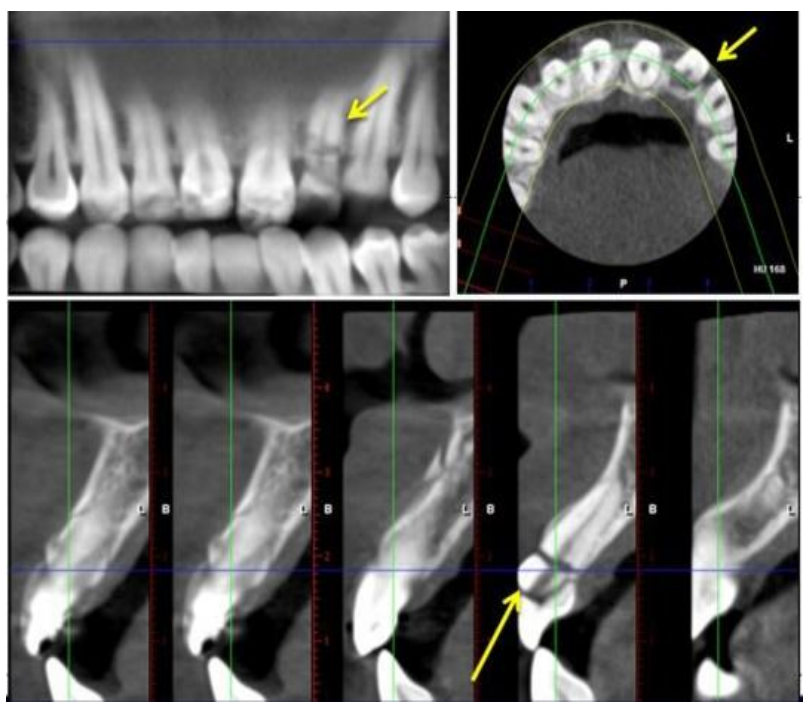

Fig-3: Preoperative CBCT

Treatment options were discussed with the patient. The treatment plan implicated Conventional Root Canal treatment of 11,21 and Extraction followed by Immediate implant placement on 22 using Socket Shield Technique. Patient consent was obtained.

Following local anesthesia of the treatment site, 22 was decoronated (Fig-4). The root was then sectioned mesiodistally and longitudinally through the root with the canal as a reference point using a long shank root resection bur coupled to a hydrated highspeed handpiece. The labial and palatal halves were separated from each other entirely from the coronal to the apical aspect. Periotomes were then inserted between the palatal root section and the alveolar socket 
wall to sever the PDL. Palatal root section was then carefully extracted (Fig-5).

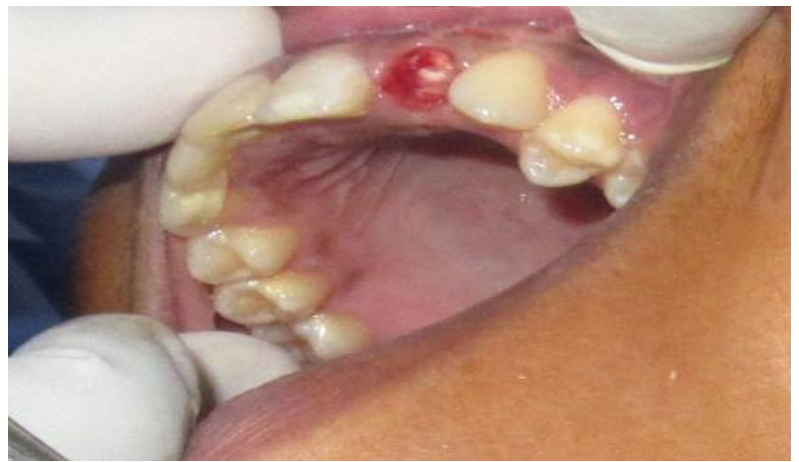

Fig-4: Decoronated 22

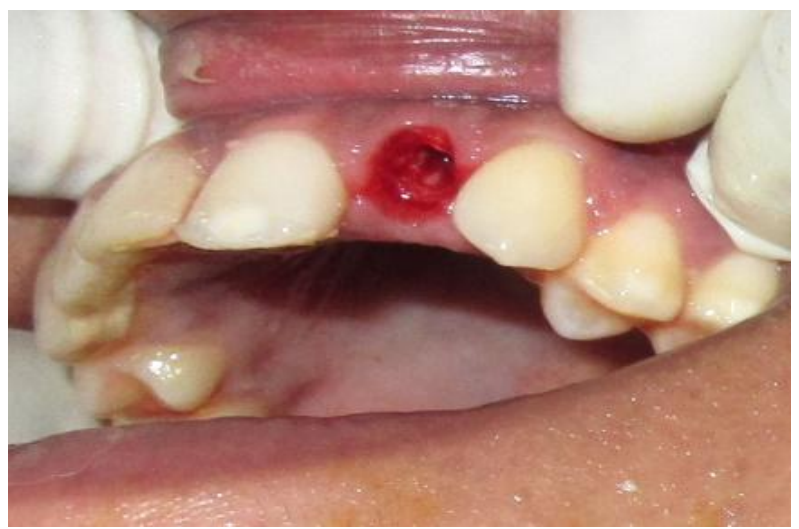

Fig-5: Palatal root section extracted

The labial root section that remained in situ was then instrumented on its inner aspect with a sharp probe and was inspected for immobility. The socket was gently curretted and irrigated with normal saline. An osteotomy at the palatal wall of the extraction socket was prepared (Fig-6) and a $3.75^{*} 16 \mathrm{~mm}$ implant (Zimmer Dental Implants, Treviso, Italy) was placed palatal to the prepared Socket Shield (Fig-7). The buccal jump gap (gap between implant and socket shield) was grafted with bone graft (OSSEOGRAFT, DMBM). Healing was uneventful. Following suture removal a temporary removable partial denture with tissue surface relieved in the implant site was inserted.

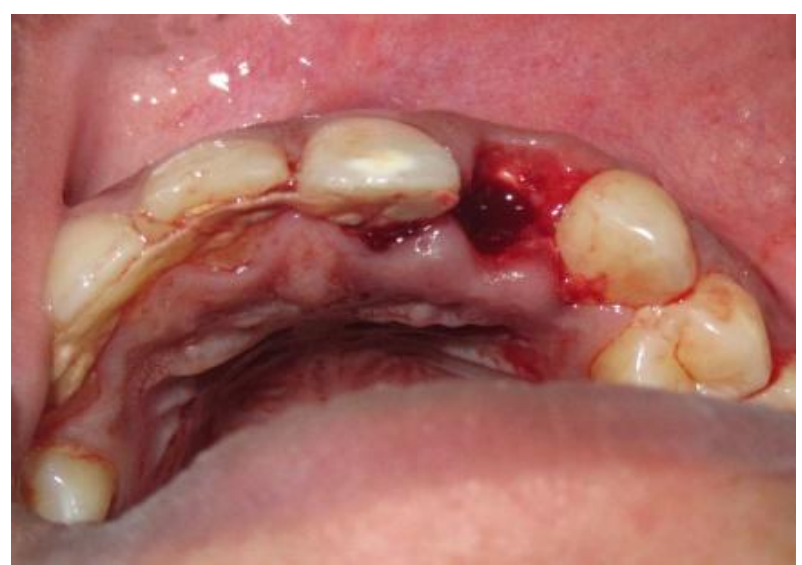

Fig-6: Osteotomy site with Buccal Shield

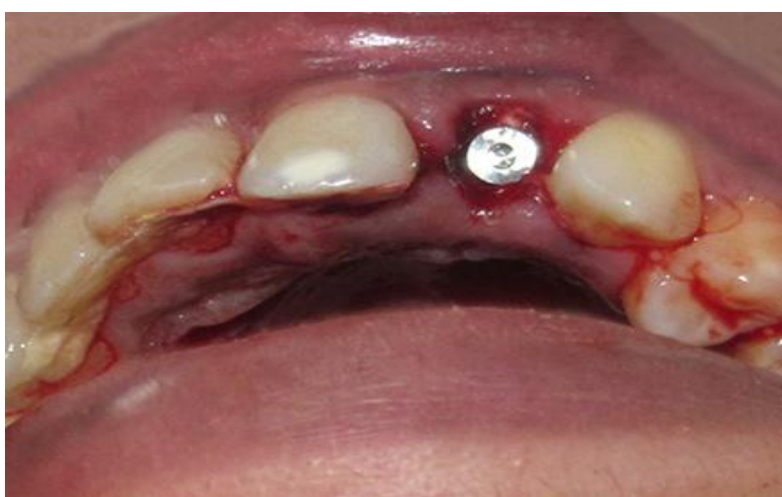

Fig-7: $3.75 * 16 \mathrm{~mm}$ implant placed

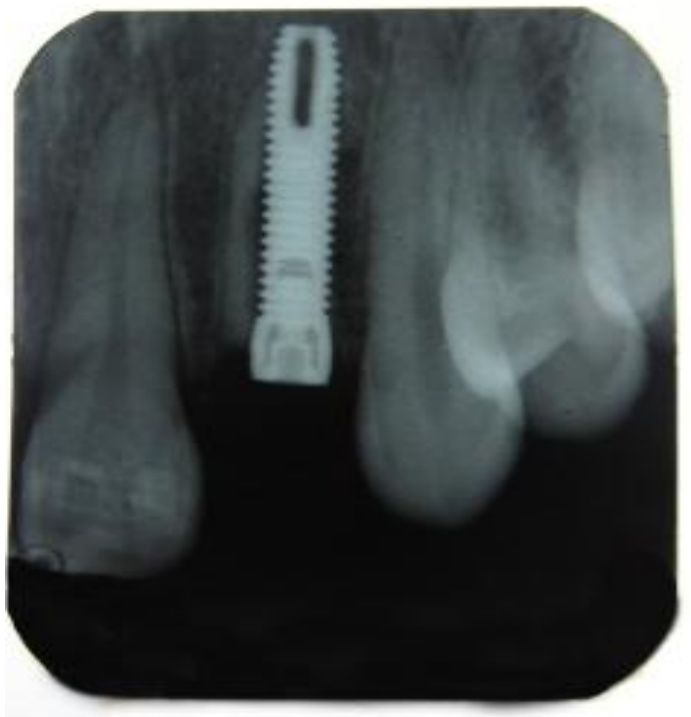

Fig-8: Immediate post operative radiograph

After six months of healing, the patient reported for restorative phase of treatment. The implant was restored with a cement retained metal ceramic crown using an angulated abutment. Post endodontic restoration (Metal ceramic crown) was cemented on 11 and 21 (Fig 9, 10). The patient was satisfied with the aesthetic and functional outcomes achieved.

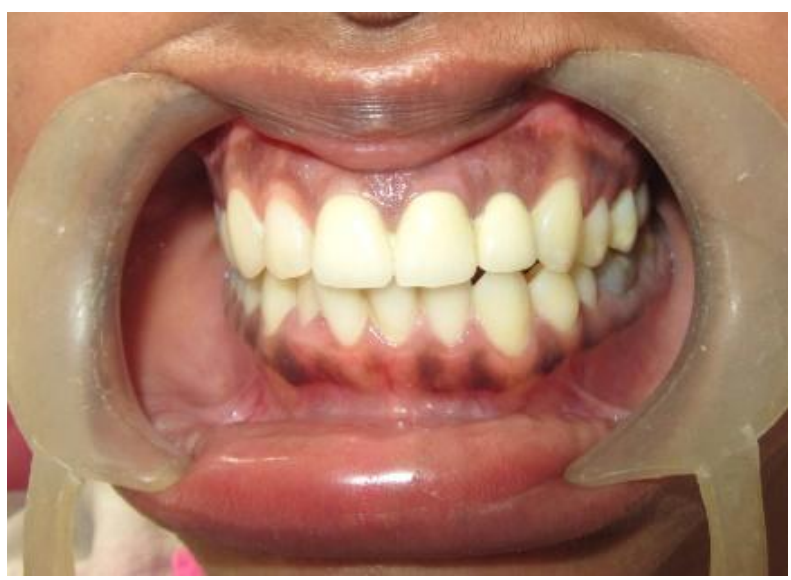

Fig-9: Final Prosthesis (Frontal View) 


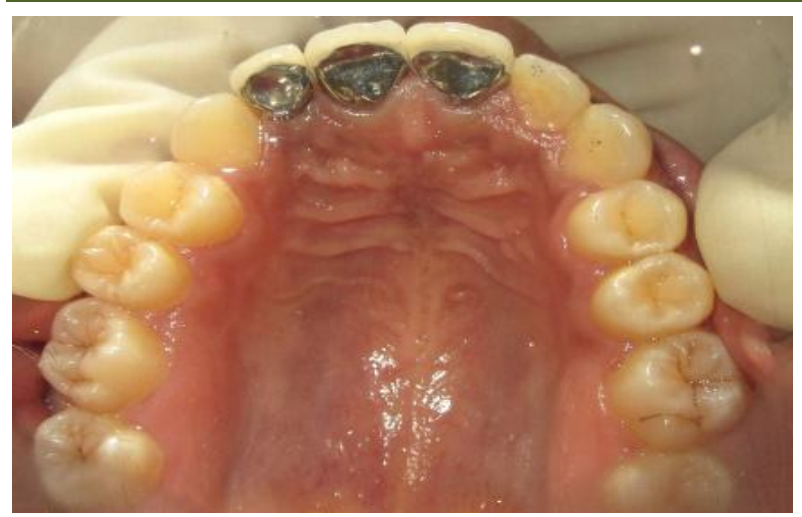

Fig-10: Final Prosthesis (Palatal View)

At one year post loading follow up visit, the tooth showed no sign of gingival recession and the height and contour of the alveolar ridge was well preserved. Radiograph revealed very minimal amount of alveolar crestal bone loss (Fig 11, 12, 13, 14).

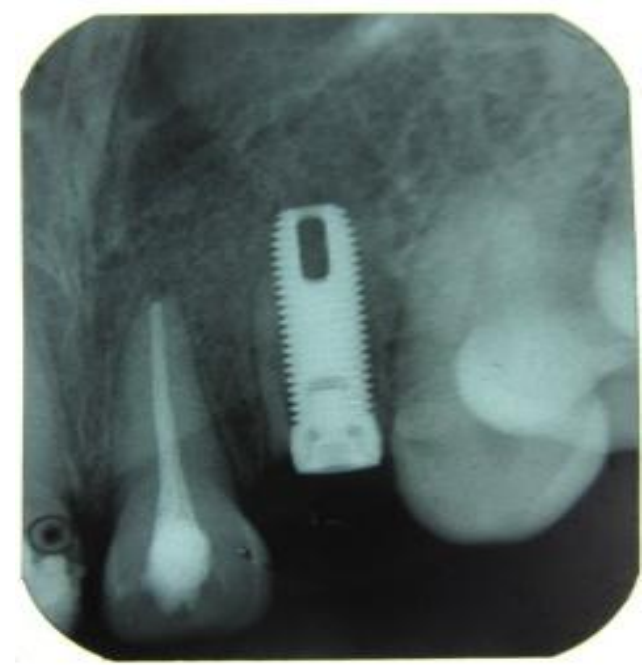

Fig-11: Two months post operative radiograph

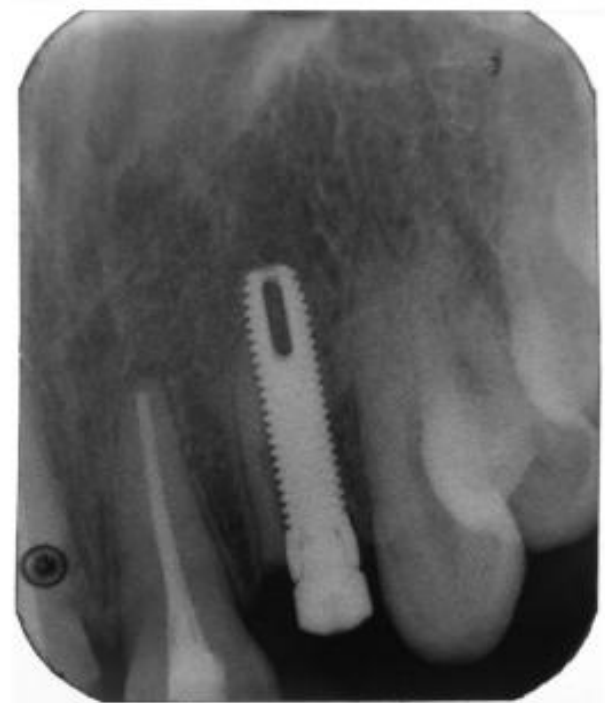

Fig-12: Six months post operative radiograph

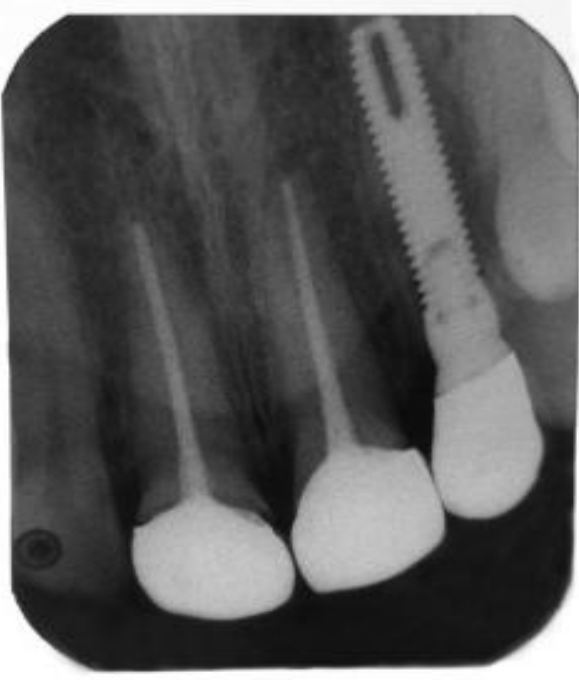

Fig-13: Immediate post loading Radiograph

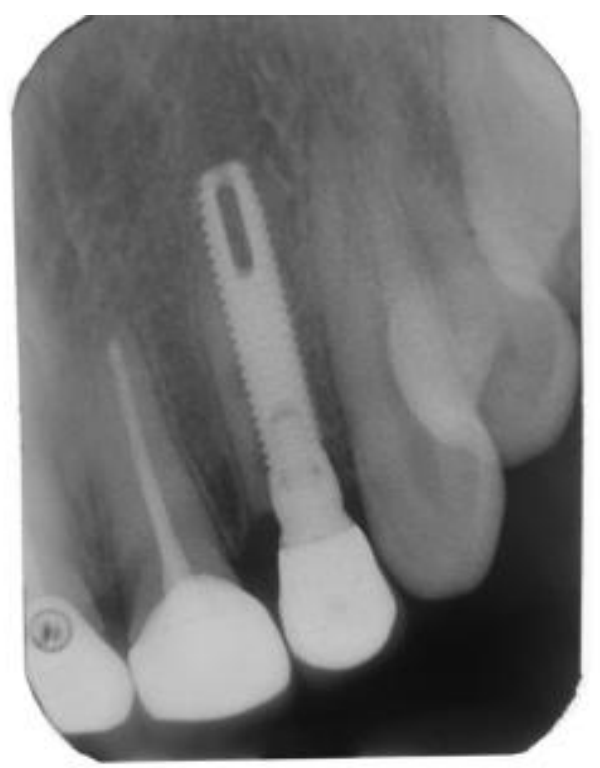

Fig-14: One year post loading Radiograph

\section{CASE REPORT - 2}

A 55 year old female patient reported to Government Dental College, Kottayam with a chief complaint of fractured upper front tooth. Intra oral examination revealed an endodontically treated upper left lateral incisor fractured at the level of crest of bone. Neither surgical crown lengthening nor orthodontic extrusion was feasible because of inadequate crown root ratio. Extraction followed by immediate implant placement, retaining the buccal root fragment was the treatment of choice. The site was anesthetized. Root was sectioned into facial and palatal sections, with palatal section bearing the whole of root canal and apex (Fig 15). Palatal root fragment was gently luxated and extracted (Fig 16, 17). All remnants of infection within the socket apex was thoroughly curetted out, followed by copious saline rinse. Implant bed was prepared. A $3.75^{*} 17 \mathrm{~mm}$ (Adin Dental Implant System Ltd, Afula, 
Israel) implant was placed (Fig-18). Prosthetic rehabilitation was done using a screw retained metal ceramic crown after six month.

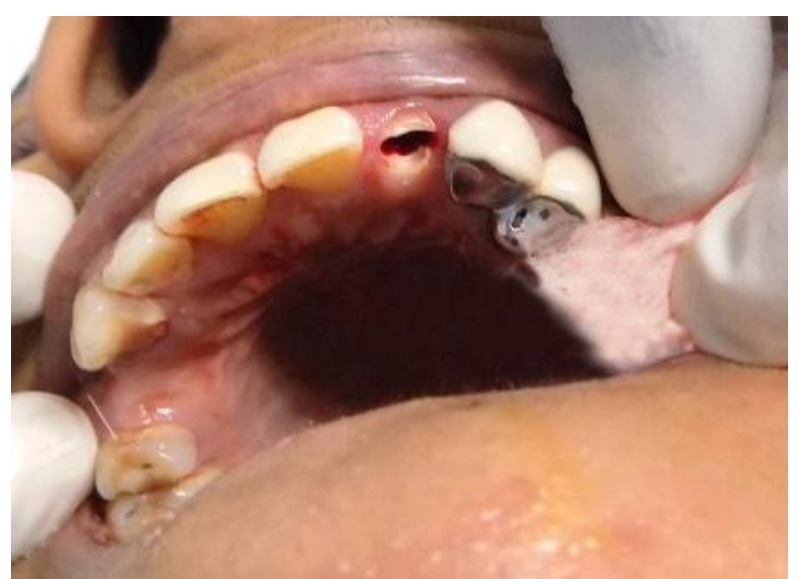

Fig-15: Root sectioned into facial and palatal sections

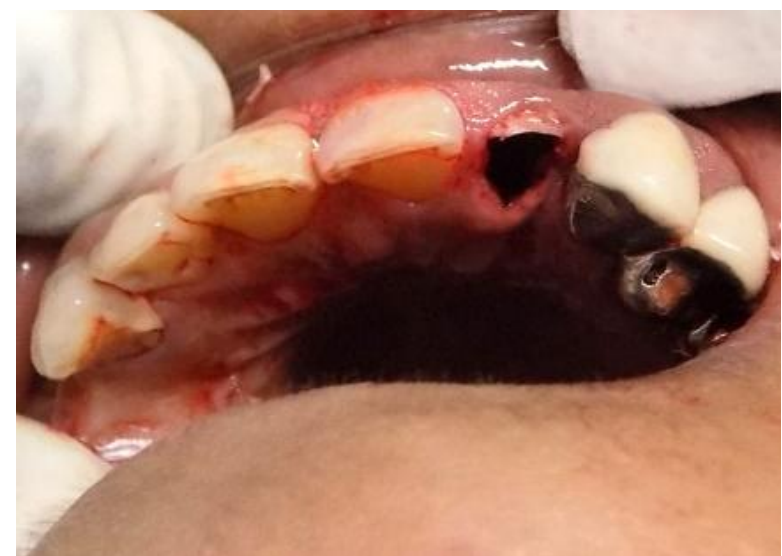

Fig-16: Palatal root section extracted

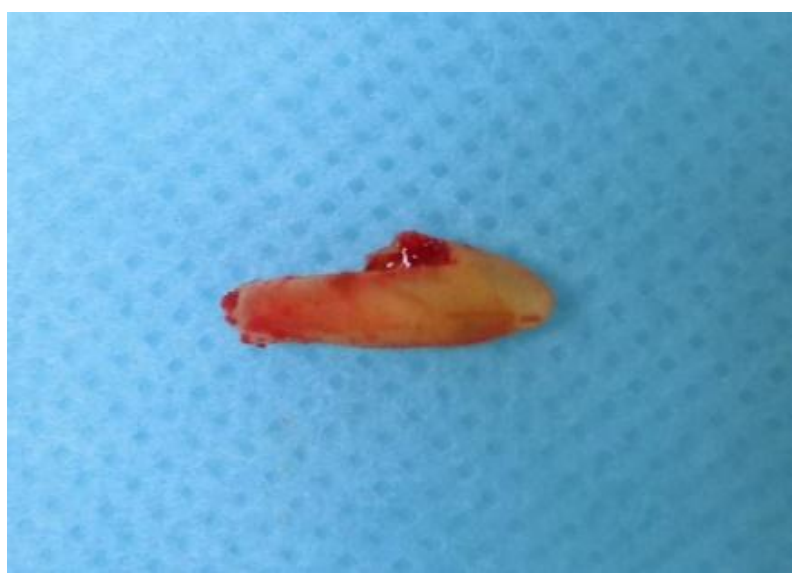

Fig-17: Extracted palatal root section

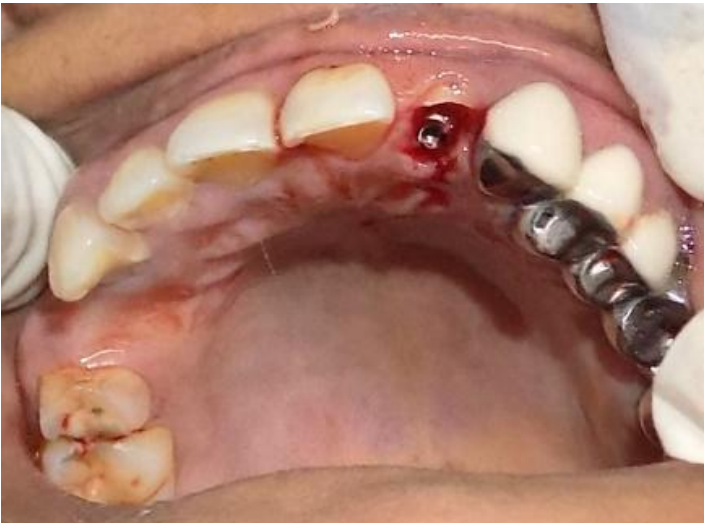

Fig-18: 3.75* $17 \mathrm{~mm}$ implant placed

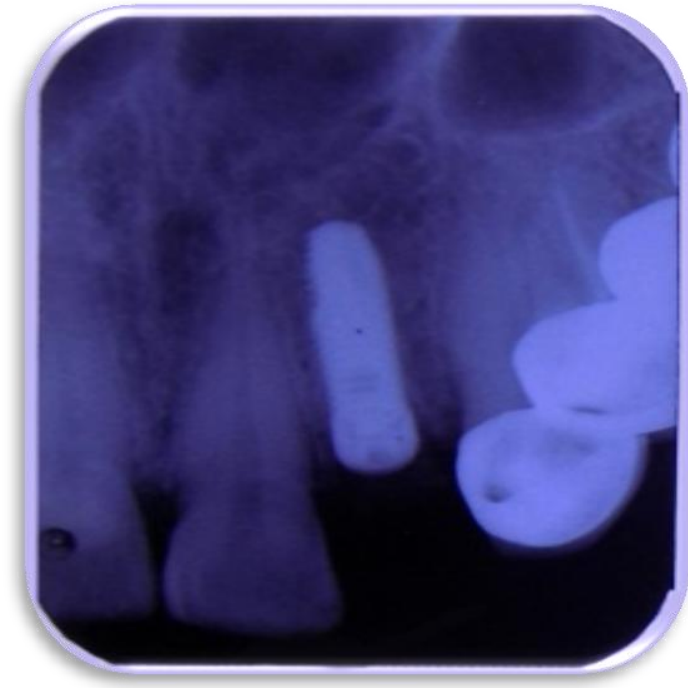

Fig-19: Immediate postoperative radiograph

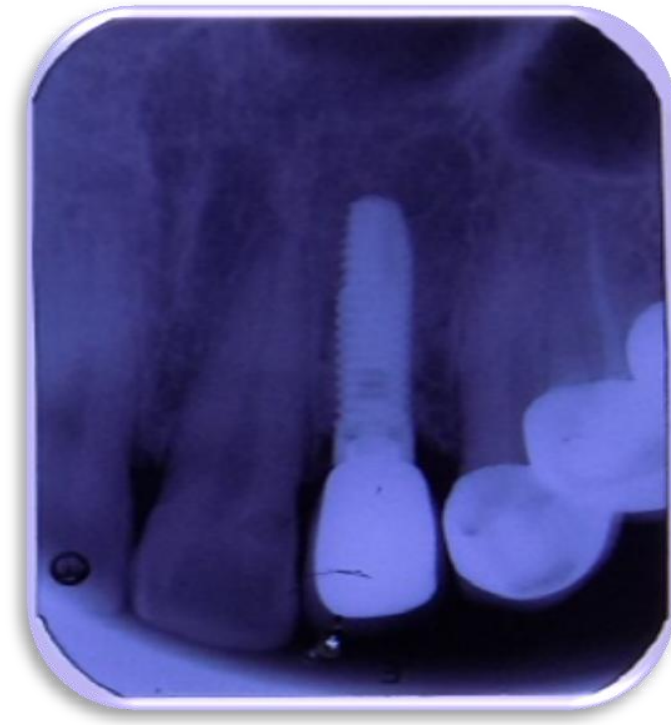

Fig-20: Immediate post loading radiograph 


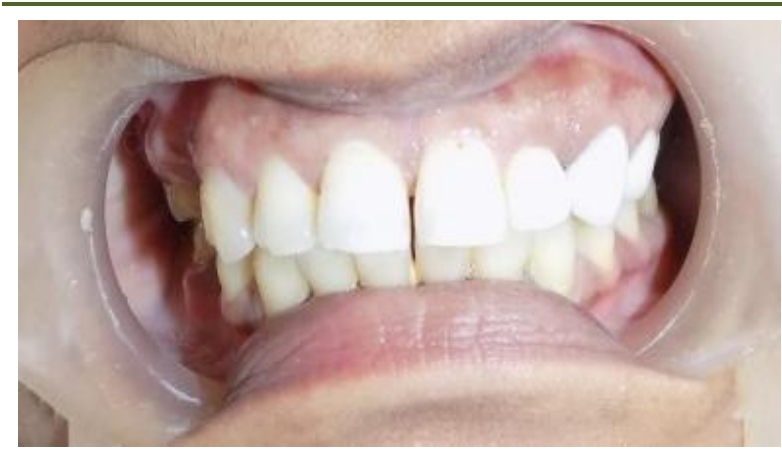

Fig-21: Final prosthesis

\section{DISCUSSION}

In spite of the multitude of ridge preservation and ridge augmentation techniques available utilizing a wide variety of materials, resorption of the post extraction socket is inevitable. Partial Extraction Therapy relies on the principle that, if remaining part of a tooth's root is in perfect condition, it can be gingivally submerged and thus preserve the bone structure. Partial extraction therapy treats the underlying cause of the resorption, i.e., it prevents the loss of vital periodontal tissues around the tooth, and thus maintains the Bundle Bone -Periodontal Ligament complex (BB - PDL complex) with its vascular supply [3].

Miller et al., in 1958 emphasized the importance of retaining the tooth root as a 'Biologic Stabilizer' to improve the support and stability of complete dentures. He added that it behooves us, as physicians, surgeons, and physiologists of the oral cavity, to preserve to the very best of our ability, that which has not been lost. The healing arts are intended to aid and add to the life of living tissue, not to destroy it [9]. Malmgren et al., in 1984 reported successful tissue regeneration around submerged tooth roots of ankylosed tooth and that bone forms coronal to such submerged teeth [10]. O'Neal et al., in a similar study on dogs showed that osteocementum and a connective tissue layer had formed between the tooth surface and the newly formed bone [11].

Salama et al., in 2007 while restoring multiple adjacent teeth in the esthetic zone, used RST for developing pontic sites to preserve the entire attachment apparatus as well as for complete preservation of the alveolar ridge for improved esthetics. Root Submergence Technique prevents epithelial down growth in periodontal regeneration procedures and maintain the alveolar ridge height and frame. Gingival tissue perforation and cyst formation are the proposed complications, however necrotic and infected dental pulps have seldom been reported [12].

However, in this report, contrary to the above cited studies only the buccal part of the root and its supra-periosteal attachments were preserved and an implant is placed engaging the palatal socket wall immediately. These implants achieved osseointegration without any sign of peri implant inflammation and were able to adequately maintain the contour of the ridge.

In the first scientific literature on Socket Shield, Hurzeler demonstrated the histology of a healed socket-shield in contact with an osseointegrated implant palatal to it. The tooth fragment was attached to the buccal bone plate by a physiologic periodontal ligament and on the lingual side of the fragment, newly formed cementum with cementoids and cementoblasts was detected. The space between the implant threads was partially filled with an amorphous mineralized tissue. The socket shield also showed no osteoclastic remodeling. In this study, an enamel matrix derivate (Emdogain ${ }^{\circledR}$, Straumann, Basel, Switzerland) was applied to the inner surface of socket shield before implant placement, which resulted in a layer of new cementum [5]. Bäumer D et al., in a similar study evaluated the reaction of the surrounding tissues without the use of Emdogain. The small gap between implant and tooth was filled with new bone with no signs of resorption [13]. Schwarz et al., found that Reparative Dentine was formed on exposed dentinal surface of retained fragment due to trauma during implant site preparation. The author used the term 'Dentointegration' to describe the mineralized tissue formed at implant -tooth interface [14].

Bäumer D et al., also analyzed the clinical volumetric change of the alveolar ridge and showed a mean loss of $0.88 \mathrm{~mm}$ in labial direction (a maximum of $1.67 \mathrm{~mm}$ and a minimum of $0.15 \mathrm{~mm}$ ). Bone loss was more pronounced in middle area and decreasing toward the mesial and distal regions of the tooth [13]. The maximum amount of horizontal resorption on the buccal side of a premolar restored with a similar technique was $0.72 \mathrm{~mm}$ [15].

The term Root Membrane was coined by Siompas et al., to describe the technique of intentional retention of facial aspect of root to minimize volumetric alterations at implant site. The term 'root membrane' is a more appropriate one as it shifts the focus to maintanence of Root fragment. No bone graft or biomaterial was used to fill the jump gap in their study [16].

Many authors have described modifications to the original technique of Socket Shield. Markus Glocker modified conventional socket shield technique by retaining the buccal tooth fragment and followed a delayed implantation after a period of 6 months, clearly evaluating the amount of new bone formed [17]. Kan and Rungcharassaeng described proximal socket shield technique to maintain the interimplant papilla when replacing a failing tooth adjacent to an implant restoration. Socket Shield is sectioned into mesial and distal parts for the purpose of papillae preservation. The prepared proximal root fragment must be of uniform thickness (1.5 to $2.0 \mathrm{~mm})$ and must occupy the 
complete root length with a minimum 2-mm supracrestal portion [18].

The ROOT-T-BELT METHOD is yet another modification of the socket shield technique, involving implant placement surrounded by root remainder (periodontium, cement and dentin), creating a belt-like structure that prevents any displacement as well as preserves all $360^{\circ}$ of bone structure [4].

Socket Shield is difficult to prepare in small roots as in lower anteriors and curved roots as in posteriors. A tooth indicated for extraction with apical pathology is not an absolute contraindication, however mobility of tooth root due to traumatic occlusion or active periodontitis $(>3 \mathrm{~mm}$ attachment loss) are absolute contraindication for Socket Shield Technique. Tooth with vertical root fracture may also be considered for Socket shield in contrast to Root Submergence. The prepared socket shield mobility may also hamper the success of the treatment [19].

Socket Shield should be reduced approximately to half the thickness from root canal to its labial limit. The shield should not be excessively reduced as it might affect its stability. The coronal portion may be thinner but the apical thickness should be maintained. Sharp edges and overextension above the alveolar crest should also be avoided as it may result in eventual exposure through the soft tissue [19].

It is a single stage surgical procedure not only combining extraction and implant placement but also eliminating the need for future ridge augmentation procedures. The shield also assists ideal prosthetically driven positioning of implant [20]. However the procedure is highly technique sensitive and lack long term studies to evaluate its outcome and manage its complications.

\section{CONCLUSION}

The present case series describes the truly called 'PDL mediated immediate implant placement' that does not interfere with implant osseointegration and still prevent buccopalatal ridge collapse. Clinician should be extremely careful in case selection, choosing the most appropriate Partial Extraction Therapy, executing the highly technique sensitive procedure and performing close follow up. Partial extraction therapy is highly promising and holds significant potential in the field of aesthetic and restorative implant dentistry.

\section{REFERENCES}

1. Van der Weijden F, Dell'Acqua F, Slot DE. Alveolar bone dimensional changes of post extraction sockets in humans: a systematic review. Journal of clinical periodontology. 2009 Dec;36(12):1048-58.

2. Araújo MG, Sukekava F, Wennström JL, Lindhe J. Ridge alterations following implant placement in fresh extraction sockets: an experimental study in the dog. Journal of clinical periodontology. 2005 Jun;32(6):645-52.

3. Salama M, Du Toit DJ. Partial extraction therapies (PET) part 1: maintaining alveolar ridge contour at pontic and immediate implant sites. Periodontics. 2016;36:681-7.

4. Troiano M, Benincasa M, Sánchez P, Guirado JC. Bundle bone preservation with Root-T-Belt: case study. Ann Oral Maxillofac Surg. 2014 Apr;2(1):7.

5. Hürzeler MB, Zuhr O, Schupbach P, Rebele SF, Emmanouilidis N, Fickl S. The socket- shield technique: a proof of principle report. Journal of clinical periodontology. 2010 Sep;37(9):855-62.

6. Choi S, Yeo IS, Kim SH, Lee JB, Cheong CW, Han JS. A root submergence technique for pontic site development in fixed dental prostheses in the maxillary anterior esthetic zone. Journal of periodontal \& implant science. 2015 Aug 1;45(4):152-5.

7. Gluckman H, Salama M, Du Toit J. Partial Extraction Therapies (PET) Part 2: Procedures and Technical Aspects. International Journal of Periodontics \& Restorative Dentistry. 2017 May 1;37(3):377-385.

8. Botticelli D, Berglundh T, Lindhe J. Hard- tissue alterations following immediate implant placement in extraction sites. Journal of clinical periodontology. 2004 Oct;31(10):820-8.

9. Miller PA. Complete dentures supported by natural teeth. Journal of Prosthetic Dentistry. 1958 Nov 1;8(6):924-8.

10. Malmgren B, Cvek M, Lundberg M, Frykholm A. Surgical treatment of ankylosed and infrapositioned reimplanted incisors in adolescents. European Journal of Oral Sciences. 1984 Oct;92(5):391-9.

11. O'Neal RB, Gound T, Levin MP, Carlos E. Submergence of roots for alveolar bone preservation: I. Endodontically treated roots. Oral Surgery, Oral Medicine, Oral Pathology. 1978 May 1;45(5):803-10.

12. Salama M, Ishikawa T, Salama H, Funato A, Garber D. Advantages of the Root Submergence Technique for Pontic Site Development in Esthetic Implant Therapy. International Journal of Periodontics \& Restorative Dentistry. 2007 Dec 1;27(6): 521-527.

13. Bäumer D, Zuhr O, Rebele S, Schneider D, Schupbach P, Hürzeler M. The socket- shield technique: first histological, clinical, and volumetrical observations after separation of the buccal tooth segment-a pilot study. Clinical implant dentistry and related research. 2015 Feb;17(1):71-82.

14. Schwarz F, Mihatovic I, Golubovic V, Becker J. Dentointegration of a titanium implant: a case report. Oral and maxillofacial surgery. 2013 Sep 1;17(3):235-41. 
15. Chen CL, Pan YH. Socket shield technique for ridge preservation: a case report. Journal of Prosthodontics and Implantology. 2013 Dec $1 ; 2(2): 16-21$.

16. Siormpas KD, Mitsias ME, Kontsiotou-Siormpa E, Garber D, Kotsakis GA. Immediate Implant Placement in the Esthetic Zone Utilizing the "Root-Membrane" Technique: Clinical Results up to 5 Years Postloading. International Journal of Oral \& Maxillofacial Implants. 2014 Dec 1;29(6):1397-1405.

17. Glocker M, Attin T, Schmidlin PR. Ridge preservation with modified "socket-shield" technique: a methodological case series. Dentistry Journal. 2014 Mar;2(1):11-21.
18. Kan JY, Rungcharassaeng K. Proximal socket shield for interimplant papilla preservation in the esthetic zone. International Journal of Periodontics \& Restorative Dentistry. 2013 Jan 1;33(1):e24e31.

19. Du Toit J. The pontic-shield: partial extraction therapy for ridge preservation and pontic site development. Periodontics. 2016;36:417-23.

20. Mitsias ME, Siormpas KD, Kontsiotou-Siormpa E, Prasad H, Garber D, Kotsakis GA. A Step-byStep Description of PDL-Mediated Ridge Preservation for Immediate Implant Rehabilitation in the Esthetic Region. International Journal of Periodontics \& Restorative Dentistry. 2015 Nov $1 ; 35(6): 835-841$. 